\title{
Drought Trends in the Iberian Peninsula over the Last 112 Years
}

\author{
P. Páscoa, ${ }^{1}$ C. M. Gouveia, ${ }^{1,2}$ A. Russo, ${ }^{1}$ and R. M. Trigo ${ }^{1}$ \\ ${ }^{1}$ Instituto Dom Luís, Faculdade de Ciências da Universidade de Lisboa, Campo Grande, Edifício C8, Piso 3, 1749-016 Lisboa, Portugal \\ ${ }^{2}$ Instituto Português do Mar e da Atmosfera, Lisboa, Portugal
}

Correspondence should be addressed to P. Páscoa; ppramos@fc.ul.pt and A. Russo; acrusso@fc.ul.pt

Received 9 July 2017; Revised 17 September 2017; Accepted 3 October 2017; Published 31 October 2017

Academic Editor: Eduardo García-Ortega

Copyright (C) 2017 P. Páscoa et al. This is an open access article distributed under the Creative Commons Attribution License, which permits unrestricted use, distribution, and reproduction in any medium, provided the original work is properly cited.

\begin{abstract}
The Iberian Peninsula (IP) is a drought-prone area located in the Mediterranean which presents a significant tendency towards dryness during the last decades, reinforcing the need for a continuous monitoring of drought. The long-term evolution of drought in the IP is analyzed, using the Standardized Precipitation Evaporation Index (SPEI) and the Standardized Precipitation Index (SPI), for the period of 1901-2012 and for three subperiods: 1901-1937, 1938-1974, and 1975-2012. SPI and SPEI were calculated with a 12-month time scale, using data from the Climatic Research Unit (CRU) database. Trends in the drought indices, precipitation, and reference evapotranspiration $\left(\mathrm{ET}_{0}\right)$ were analysed and series of drought duration, drought magnitude, time between drought events, and mean intensity of the events were computed. SPI and SPEI significant trends show areas with opposite signals in the period 1901-2012, mainly associated with precipitation trends, which are significant and positive in the northwestern region and significant and negative in the southern areas. Additionally, SPEI identified dryer conditions and an increase in the area affected by droughts, which agrees with the increase in $\mathrm{ET}_{0}$. The same spatial differences were identified in the drought duration, magnitude, mean intensity, and time between drought events.
\end{abstract}

\section{Introduction}

In recent decades, changes in climate have affected not only the average in temperature and precipitation but also the frequency of extreme events causing impacts on natural and human systems on all continents and across the oceans $[1,2]$. Nevertheless, increases in climate variability have a greater effect on society than changes in mean climate because it is more difficult to adapt to changes in extremes [3]. The last major assessments performed by the IPCC on extreme events $[1,2]$ confirm that a changing climate can lead to changes in the frequency, intensity, spatial extent, duration, and timing of weather and climate extremes that combined with larger exposure can result in unprecedented risks to humans and ecosystems [1]. Several studies have also stressed the role played by recent climate change in the increased likelihood of occurrence of some of these extremes [4-7]. In particular, the observed impacts of droughts in western Mediterranean area are mounting [8-10]. At the European scale, droughts can have huge economic impacts, as shown by recent estimation of 100 billion Euros of losses inflicted by droughts between 1976 and 2006 [11]. Consequently, it is crucial to ensure a continuous monitoring of drought, as well as a deeper capacity of modelling its variability and impacts on environment, society, and economic activities. Nevertheless, a quantitative assessment of drought characteristics is revealed to be very challenging, particularly due to the existence of several definitions of drought [12], as well as of different criteria used to determine the onset, end, and duration of a dry event. This challenge is further increased by the difficulty of quantification of drought by means of a specific observational dataset, together with the sparsity of the available historical records of soil moisture [13]. Thus, in the last two decades, several drought indices have been developed, with the aim to monitor dry (and wet) episodes, using precipitation and temperature datasets [14-16], as well as satellite information [17, 18]. The systematic analysis of drought evolution and severity has been traditionally performed through the computation of the Palmer Drought Severity Index (PDSI) [19] or of the multiscalar Standardised Precipitation Index (SPI) [20]. More recently, a new formulation of the not so generalist PDSI, the so-called self-calibrated PDSI (scPDSI), was developed and used successfully to assess droughts over the Mediterranean region [21, 22]. As different systems and regions respond to 
drought at very diverse temporal scales, some of the abovementioned drought indices present some caveats considering that they are unable to produce a multiscale outcome. Thus, the analysis of droughts for distinct time scales is frequently performed using multiscalar drought indices, such as the SPI $[20,23]$, which uses precipitation data to identify dry/wet conditions, and more recently the Standardized Precipitation Evaporation Index (SPEI) [16], which uses a simple water balance, incorporating evapotranspiration and indirectly several related climate variables that play an important role in drought occurrence and characterization.

A clear trend towards drier conditions during the 20th century over Mediterranean Europe, including the Iberian Peninsula (IP), has been identified in several studies performed by means of drought indicators [24-26], although the period ranging from the 1940s until the 1970s does not present the same trend [26]. Different sources of data have been used to compute drought indicators including observations from meteorological stations [26-28], gridded datasets [22, 29], and reanalysis datasets [30]. Several authors have provided evidences of an increasing number of droughts forced by higher temperatures and enhanced dry conditions [28, 31, 32]. However, there are still several uncertainties related to observed global scale drought trends $[33,34]$, mainly due to the opposite trends identified in many regions. Additionally, Ficklin et al. [35] reinforced the regional character of drought events, emphasizing the need for a regional assessment of this phenomenon and consequently the added value of the regional analyses of the driving forces of drought trend conditions for regional management plans that should reduce the vulnerability of the different systems and minimize the drought impacts [36].

Severe and long drought events are frequent in the IP, with strong effects in ecosystems and the related social and economic impacts $[10,18]$. In the last decades, the severity of droughts in the IP has increased, together with an increased tendency for dryness and decrease of vegetation cover, due to the higher atmospheric evaporative demand [28, 37]. These agree with the findings of Greve et al. [38] that identified the Southwest of the IP as one hot spot of the pattern "dry gets drier." The need for a deeper knowledge of drought frequency, duration, and intensity over the IP during the last century is reinforced by the findings by Hoerling et al. [39] using Sea Surface Temperature data that have shown that the period of 1970-2010 over the Mediterranean region was considered drier when compared with 1901-1970. Together with the increasing dryness, the projections pointing for an increase of drought conditions during the 21st century [39] will tend to exacerbate these problems. However, and to the best of our knowledge, there is no regional study covering equally the entire IP (including Portugal) which analyzes drought evolution for such a long period (112 years), disentangling the drought behavior in 3 subperiods characterized by different historical, social, and climate conditions. In particular, when assessed on a long-term period, global temperature trends present breakpoints around the years 1945 and 1975, corresponding to the start and ending dates of a cooling period, preceded and succeeded by two warming periods $[40,41]$. These temperatures breakpoints have been identified in studies at a continental scale in Europe [42] and at a country scale in Portugal [43] and Spain [44], and their effect on drought trends should be taken into consideration.

Thus, our analysis aims to characterize for the first time the long-term evolution of drought in the IP for more than one hundred years (1901 to 2012) by means of two multiscalar indices, SPI and SPEI, as obtained from the Climate Research Unit TS3.21 high-resolution gridded dataset $\left(0.5^{\circ} \times 0.5^{\circ}\right)$. An additional aim was associated with the low number of meteorological stations over Western Iberia in the majority of the works, namely, in the case of the works by Coll et al. [26] that used only two stations in Portugal and 1 in the northwestern region of Spain. Furthermore, the identification of the above-mentioned temperature breakpoints motivated the separated assessment and characterization of drought events for three consecutive subperiods (1901-1937, 1938-1974, and 1975-2012) within the 112-year long-term period. To the best of our knowledge there are no other studies that perform such type of analysis using multiscalar drought indicators. Moreover, we will also assess if the observed trends of dryness severity and area affected by drought in Iberia as obtained using CRU dataset are similar to the ones obtained by other authors. Finally, it will be assessed for the first time the longterm trends of drought duration, drought magnitude, time between drought events, and mean drought intensity at grid point scale. At the European scale, a study performed by Spinoni et al. [25] focusing on the drought climatologies and trends analysis was performed covering only the period from 1950 onwards. We are sure that the inclusion of the previous 50 years allows a better understanding of climate extremes in the first half of 20th century. This analysis, combined with the spatial patterns of droughts over the IP during the long-term period of 112 years, together with the spatial pattern observed for the three subperiods will allow increasing the knowledge of drought trends evolution and their temporal variability on a climatic perspective, disentangling the roles played by diminishing precipitation, and increasing evapotranspiration, while identifying extreme events and IP most drought-prone areas.

\section{Data and Methods}

2.1. Data and Drought Indices. The climatic data used to compute the drought indices were obtained from the Climate Research Unit TS3.21 database [45], covering the period from January 1901 to December 2012. The dataset covers uniformly the globe and includes monthly values of several climate variables (e.g., precipitation, temperature, cloud cover, and vapor pressure, among others) computed on a high-resolution grid (0.5 × 0.5 degrees $)$.

The CRU dataset derives from thousands of stations scattered nonrandomly across the Earth, with much higher densities at mid-latitudes than in the tropics or the Arctic. Although, in terms of temporal bias, the CRU dataset logically contains many fewer observations in the early part of its record, this happens mostly in the tropical and Arctic regions [46], thus not affecting so much the more covered mid-latitude regions. Despite the smaller number of meteorological stations used to obtain the data in the first 
half of the 20th century when compared to the remaining years, Harris and coauthors [45] show that their precipitation and temperature time series have a high correlation value with other datasets [45]. Macias-Fauria and coauthors [46] show that for global studies the analyses should be undertaken using data after 1950s. However, the analysis of the present work is restricted to the IP region which includes a relatively homogeneous number of stations. Additional information about the number of stations for the considered variables in several years along the 20th century and also the methods used for interpolation and the representativeness of the available data is also provided in New et al. [47] and Mitchell and Jones [48]. According to these authors the dataset is useful for a variety of climatic applications including hydrological modelling, climate change scenarios, and evaluation of regional climate models. Moreover, this database has been previously used by the authors $[49,50]$, which have obtained good results in the IP, including for the earlier years [50].

In order to compute SPEI it is necessary to estimate the reference evapotranspiration $\left(\mathrm{ET}_{0}\right)$ based on an appropriate method (e.g., Thornthwaite, Hargreaves, and PenmanMonteith). The choice of the method must be made considering the meteorological data available and its possible influence on SPEI. Although the Penman-Monteith method [51-53] is generally recommended, in order to include the important effects of the available energy, humidity, and wind speed [32], it requires considerably more meteorological data than the Thornthwaite [54] and Hargreaves [55] methods. While Sheffield et al. [32] showed an increase in drought trends that may be associated with an overestimation of the Thornthwaite method, Spinoni et al. [56] opted for the Hargreaves method as it uses maximum and minimum temperatures to account for solar radiation. Additionally, the lower quality of CRU TS3.21 database in the earlier years led us to opt for a method that required fewer meteorological variables. In this work, a comparison of $\mathrm{ET}_{0}$ obtained using the three above-mentioned methods was made, being the Hargreaves method chosen since it shows a better correlation with the Penman-Monteith than the Thornthwaite method [57].

Average series of precipitation and $\mathrm{ET}_{0}$ over the entire IP were computed and subsequently the indices SPI and SPEI were computed with a 12-month time scale in order to quantify long-term drought periods. The SPI was computed using a Pearson III distribution and SPEI using a log-logistic distribution, as suggested, respectively, by Guttman [23] and Vicente-Serrano et al. [16]. The computation of both indices was made using the long-term period as the baseline period. With the aim of highlighting the differences on the ability of each index to assess the tendency for dryness over the IP, the difference between the two indices (SPEI-SPI) was also computed following the approach of Vicente-Serrano et al. [28]. Moreover, monthly values of $\mathrm{ET}_{0}$, SPI, and SPEI were also calculated for each grid point covered by the CRU database, to assess the spatial variability of drought in the IP, as suggested by the spatial variability of the precipitation regime in this territory $[58,59]$. Still, the analysis of the drought indices computed from average climate variables provided additional information to support the choice of the subperiods, as well as to assess the quality of the dataset by comparing the results with those obtained by other authors.

Drought indices allow for the identification and classification of drought or wet events, as well as for the computation of its intensity, duration, and magnitude. The intensity of an event in a given month corresponds to the value of the index on that month, and it allows qualitatively classifying the events [20]. The classification used in this work was proposed by Agnew [60] and comprises three drought classes: moderate, if $-0.84>$ index $\geq-1.28$; severe, if $-1.28>$ index $\geq-1.65$; and extreme, if $-1.65>$ index. These thresholds correspond to $0.201,0.100$, and 0.050 probability of occurrence, respectively. Drought's mean intensity should be looked at as the mean of the drought index values (using either SPI or SPEI) within a drought event. The duration of a drought event is the number of consecutive months with the index lower than a certain threshold, and the magnitude of a drought event is the sum of the index values on those months [20].

2.2. Drought Assessment. This study focuses on IP drought evolution excluding the Pyrenees, for the entire period of 112 years. According to previous works, and similar to other regions, the IP suffered nonmonotonic temperature changes during this period, with a warming period prevailing until the 1930s reported by Coll et al. [26] and again from the 1970s onwards $[26,43,44]$. A cooling period in between these two periods was also reported by Ramos et al. [43] and Brunet et al. [44], and since these temperature changes may influence the drought analysis performed by SPEI, we decided to split the 112-year period into 3 smaller periods that reflected the warming and cooling subperiods with approximately the same length: 1901-1937, 1938-1974, and 1975.

The trends of the drought indices and their difference (SPEI-SPI) were assessed, as well as the trends on precipitation and $\mathrm{ET}_{0}$, after a moving sum with a 12-month window was computed. It is a common practice to analyze annual, seasonal, or monthly precipitation and $\mathrm{ET}_{0}$, but the computation of a moving sum with the same time scale as the drought index allows identifying the influence in SPEI of changes in precipitation and $\mathrm{ET}_{0}$, as well as the influence of the precipitation in SPI. For instance, when a 12-month time scale is used to compute the drought index, the annual precipitation and $\mathrm{ET}_{0}$ account only for the drought index values on the month of December [61], which would not be sufficient to explain the behavior of the complete time series of SPEI and SPI.

Based on both SPI and SPEI indices, time series of drought duration, drought magnitude, time spanned between drought events, and mean intensity of the drought events were built for each grid point of the IP. Following the work of Spinoni et al. [25], events that lasted only one month were not considered and were merged to the contiguous events. Due to the reduced number of drought events in some of the subperiods which does not allow for a significant statistical assessment, the analysis was only performed for the long-term period (1901-2012). Based on the grid points' calculations, the percentage of area affected by drought was also determined and the results obtained with each index 


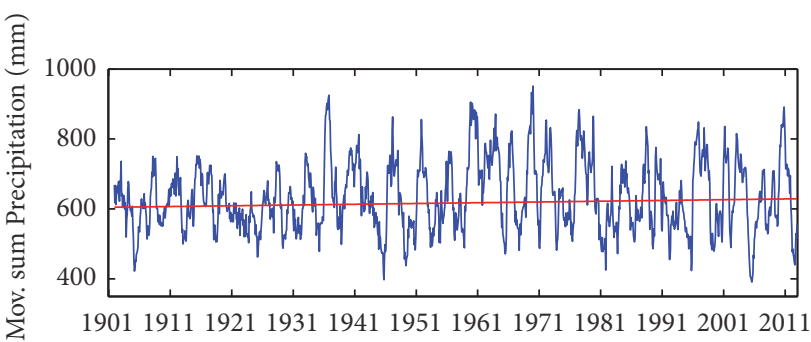

(a)

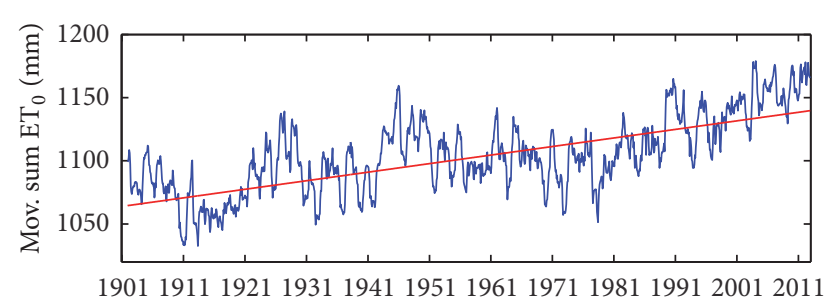

(b)

FIGURE 1: Moving sum of the spatial averaged precipitation (a) and reference evapotranspiration ( $\mathrm{ET}_{0}$ ) (b) determined by the Hargreaves method over the IP during the period 1901-2012, and the corresponding linear trend (red bold line).

were compared. The change of these time series during the period analyzed was also assessed.

2.3. Trend Analysis. The existence of significant trends in meteorological fields and drought indices was assessed based on the application of appropriate trend tests which were chosen taking into account the presence of outliers and/or autocorrelation in the analysed time series. The drought indices do not present significant outliers, but they are autocorrelated, and so it is not advisable to test the statistical significance of the trend of these time series with the standard Mann-Kendall test [22]. This caveat is also present in series derived with moving sums and moving averages, and thus it is necessary to use a more advanced test that can deal with the autocorrelation such as the modified Mann-Kendall test [62]. On the other hand, as the series of drought duration, magnitude, mean intensity, and time between drought events do not present autocorrelation, the Spearman-Rho test was used instead of the Mann-Kendall test, since the former test is less affected by outliers than the latter [63]. When using the Spearman-Rho test only time series with at least 20 points were considered, following the suggestion of Lanzante [63]. The slope and intercept were always calculated with the Theil Sen method $[64,65]$.

\section{Results}

3.1. Averages for the Iberian Peninsula. The moving sums of the precipitation and $\mathrm{ET}_{0}$ estimated with the Hargreaves method over the IP are presented in Figure 1, as well as the corresponding linear trends obtained for the entire period. Table 1 presents the statistical significance of the detected trends, the slope, and the intercept for the moving sums of precipitation and $\mathrm{ET}_{0}$. While precipitation does not present a significant trend during the long-term period, $\mathrm{ET}_{0}$ shows a marked increase, although not visible throughout the whole period (Figure 1). The trend analysis performed on the three subperiods highlights this behavior; while, in the case of precipitation, only the intermediate period presents a significant positive trend (Table 1), in the case of $\mathrm{ET}_{0}$, all the three subperiods present significant trends, being negative in the intermediate period and positive in the first and last subperiods (Table 1).

The drought indices obtained with the averaged meteorological parameters for the IP are presented in Figure 2. Both
TABLE 1: Significance (significance level of 0.05), slope (mm/year), and intercept of trends in accumulated precipitation and $\mathrm{ET}_{0}$. The slope values shown were multiplied by $10^{-3}$. NS, nonsignificant; +, significant and positive; -, significant and negative.

\begin{tabular}{lcccccc}
\hline \multirow{2}{*}{ Period } & \multicolumn{3}{c}{ Precipitation } & \multicolumn{3}{c}{$\mathrm{ET}_{0}$} \\
& Trend & Slope $^{*}$ & Intercept & Trend & Slope $^{*}$ & Intercept \\
\hline $1901-2012$ & NS & 18.5 & 609.4 & + & 56.5 & 1064.4 \\
$1901-1937$ & NS & 10.1 & 615.4 & + & 45.7 & 1069.5 \\
$1938-1974$ & + & 160.6 & 607.6 & - & 22.8 & 1106.5 \\
$1975-2012$ & NS & 4.5 & 609.4 & + & 163.8 & 1091.8 \\
${ }^{*} \times 10^{-3}$. & & & & & &
\end{tabular}

drought indices agree in identifying the longest and most intense drought events during the decades of 1940, 1950, and since the 1980s. Otherwise, whereas the 1960s and 1970s were predominantly wet, the 1910s and 1930s presented wet and dry periods shorter and less intense than in other decades [66]. Moreover, the recent 2004/2005 and 2011/2012 extreme drought events are also clearly evident on all indices. The difference between SPEI and SPI (Figure 2(c)) also presents a marked decrease and the highest differences are coincident with the periods where an increase of $\mathrm{ET}_{0}$ occurred.

Additionally, Table 2 presents the trend and corresponding statistical significance for SPI and SPEI and also for the difference between SPI and SPEI during the considered periods. SPI and SPEI show a compliant positive significant trend during the 1938-1974 period, whereas in the first period no significant trend is present. The simultaneous positive SPEI and SPI trends may be associated with the simultaneous existence of a positive trend in precipitation and nonexistence of a trend in $\mathrm{ET}_{0}$ during this period. The SPEI time series shows significant negative trends for the remaining periods. Moreover, the SPEI-SPI time series also presents a significant negative trend for all the periods (except for 1938-1974). Both negative trends in SPEI and SPEI-SPI may be explained by the existence of a positive significant trend in $\mathrm{ET}_{0}$.

3.2. Local Trends. The trends of moving sums of precipitation and $\mathrm{ET}_{0}$, for the four periods considered, are presented in Figure 3. The spatial pattern of the significant precipitation trends (values highlighted with a black dot) for the long period shows areas with opposite signals: while the northwestern region presents a positive trend, the southern region 


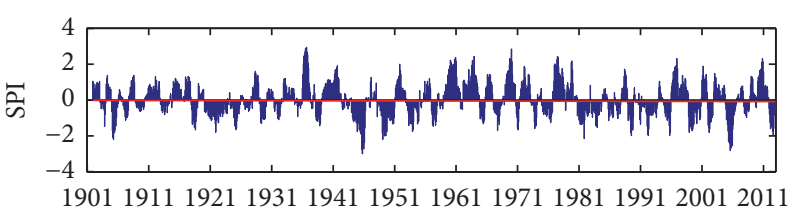

(a)

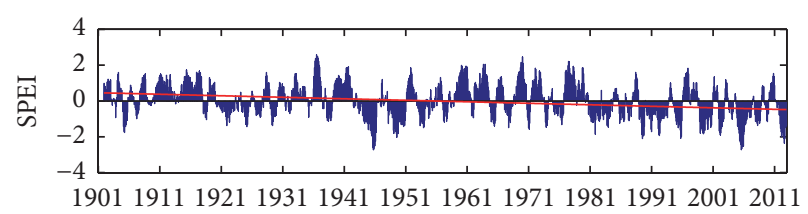

(b)

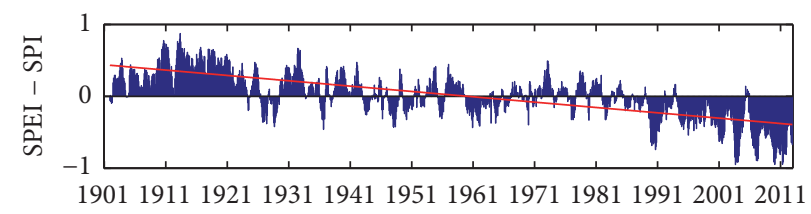

(c)

FIGURE 2: Average SPI (a) and SPEI (b) using Hargreaves' method and the difference between SPEI and SPI (c) and linear trend (red line) for the Iberian Peninsula during the period 1901-2012.

TABLE 2: As in Table 1, but for SPI, SPEI, and the difference between SPEI and SPI. The slope values shown were multiplied by $10^{-3}$.

\begin{tabular}{|c|c|c|c|c|c|c|c|c|c|}
\hline \multirow{2}{*}{ Period } & \multicolumn{3}{|c|}{ SPI } & \multicolumn{3}{|c|}{ SPEI } & \multicolumn{3}{|c|}{ SPEI-SPI } \\
\hline & Trend & Slope ${ }^{*}$ & Intercept & Trend & Slope* & Intercept & Trend & Slope ${ }^{*}$ & Intercept \\
\hline 1901-2012 & N.S. & 0.0 & -0.01 & - & 0.7 & 0.45 & - & 0.6 & 0.42 \\
\hline 1901-1937 & N.S. & 0.0 & -0.04 & NS & 0.4 & 0.29 & - & 0.6 & 0.42 \\
\hline 1938-1974 & + & 1.9 & -0.33 & + & 1.9 & -0.31 & NS & 0.1 & 0.03 \\
\hline 1975-2012 & N.S. & 0.2 & -0.24 & - & 1.7 & -0.10 & - & 1.8 & 0.17 \\
\hline
\end{tabular}

shows a negative one. Two aspects should be stressed: (i) the decadal trends in the first period are much higher than in the remaining periods, reaching trend values higher than $200 \mathrm{~mm} /$ decade in some grid points; (ii) during the last two periods, there are less grid points with significant trends than in the first period and, in the later period, these are mostly located in the North and have a negative signal. These changes are not visible in the case of the average precipitation in the IP (Figure 1), which may indicate that the increase in the North is balanced by the decrease in the South. Nevertheless, the results on the first period should be interpreted with caution, due to the lower quality of the data in the early years of the CRU TS3.21 database.

While presenting distinct spatial patterns on the different time periods, $\mathrm{ET}_{0}$ shows a consistent rising tendency (Figure $3, \mathrm{ET}_{0}$ ). In fact, the majority of the IP presents a positive trend for the complete period (1901-2012). However, both the eastern region in the first period (1901-1937) and central Portugal in the last period (1975-2012) reveal a negative trend. In agreement with the average $\mathrm{ET}_{0}$ in the IP, most of the significant trends in the intermediate period (1938-1974) are negative.

The trends for SPEI and SPI and the difference between SPEI and SPI for the considered periods are presented in Figure 4. As expected, the spatial patterns obtained for the various SPI trends are in good accordance with the corresponding spatial patterns for the precipitation (Figure 3 ). The impact of both precipitation and $\mathrm{ET}_{0}$ is evident in the results obtained for SPEI trends (Figure 4, SPEI). When compared with SPI (Figure 4, SPI), SPEI presents more significant points for the complete period, being mostly negative. The positive trends are located in the northwestern area (where precipitation has increased), and the negative trends spread throughout the central area. In the first period, the tendencies of SPEI and SPI are very similar, although SPEI presents slightly more negative trends and slightly less positive trends than SPI, which also occurs in the last period. The intermediate period is almost identical in the two cases, reflecting the small number of significant trends in $\mathrm{ET}_{0}$. In the third period, both indices present negative trends in the North and positive trends in the West, and the remaining territory presents negative trends in the case of SPEI. The influence of $\mathrm{ET}_{0}$ is more obvious in the results obtained for the difference between the two indices (Figure 4, SPEI-SPI) than for individual indices, as the spatial distribution of the trends is almost identical to the distribution of $\mathrm{ET}_{0}$ trends, although with opposite signal, as expected.

The percentage of monthly area of the IP affected by moderate drought computed using both indices and the threshold -0.84 is shown in Figure 5, as well as the difference between the area affected by the two indices and respective trend line. It is evident that the periods with the highest percentage of area affected by droughts in the IP are coincident with those identified as showing the highest drought intensity, based on the overall series (Figure 2), namely, during the decades of 1940 s and 1950s and after the 1980s. However, neither index presents a significant trend, independently of the threshold used to classify the drought events (not shown). On the other hand, the results obtained with SPEI-SPI are significant and positive (slope $=0.001$ ), being evident the positive trends in the earlier and longer periods, as well as the absence of a trend in the middle period (Figure 5(b)). The above-mentioned 

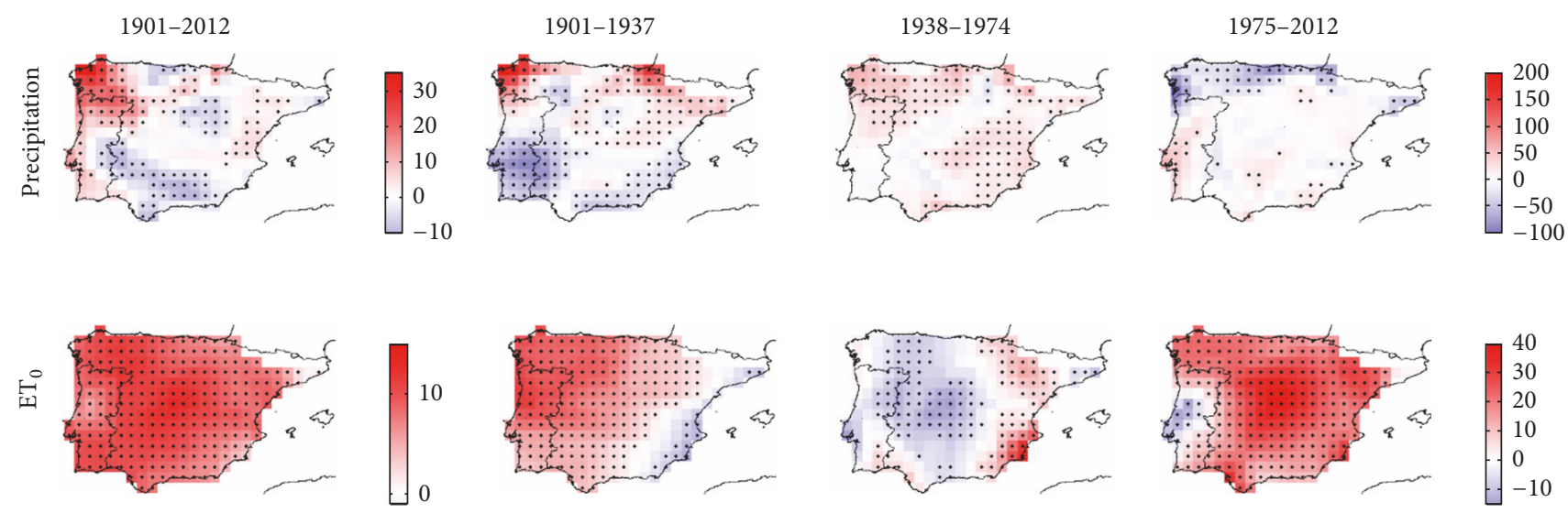

FIGURE 3: Spatial patterns of moving sums of precipitation and $\mathrm{ET}_{0}$ trends for the total period and the three subperiods considered. $\mathrm{ET}_{0}$ was estimated with the Hargreaves method. Statistically significant trends (at the $5 \%$ level) are indicated with a dot (scale is mm/decade).
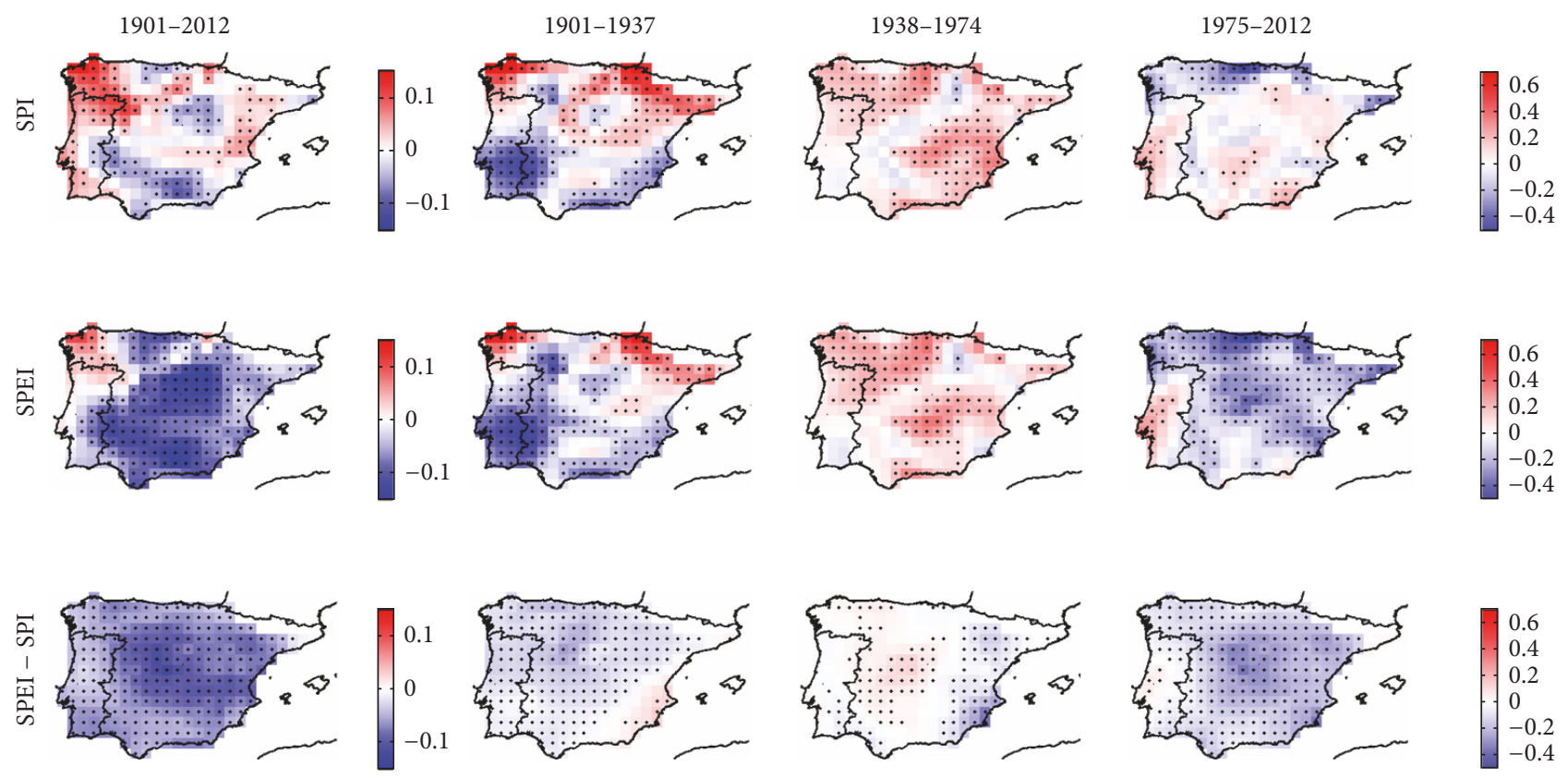

FIGURE 4: As in Figure 3, but for SPEI, SPI, and SPEI-SPI trends (scale is $z$-score/decade).

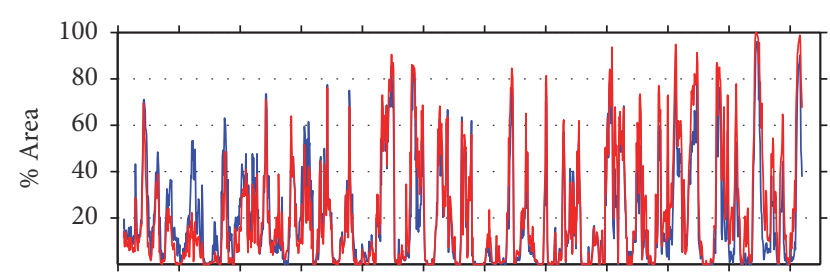

190119111921193119411951196119711981199120012011

- SPI
SPEI

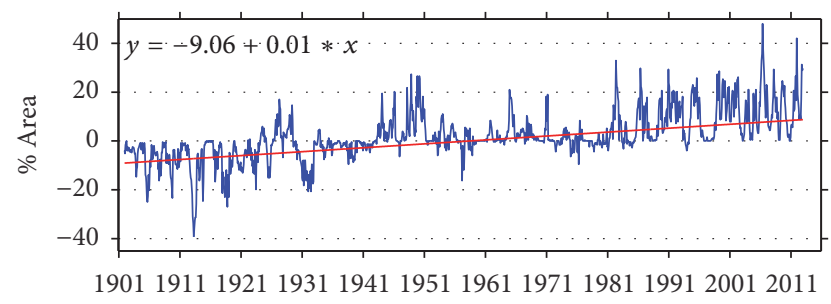

SPI
SPEI

(a)

(b)

FIGURE 5: Percentage of monthly area affected by moderate drought (index $<-0.84$ ), computed with SPEI and SPI (a), and the difference between the two (b). 
Threshold Drought duration

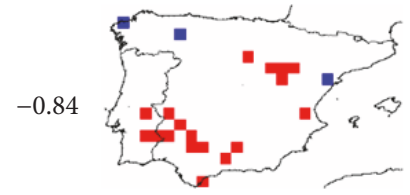

क्ष $-1.28$

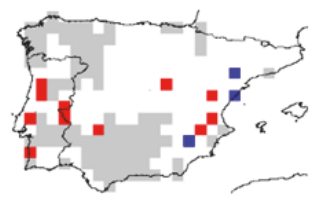

$-0.84$

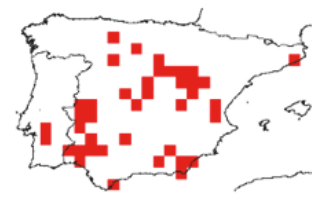

武

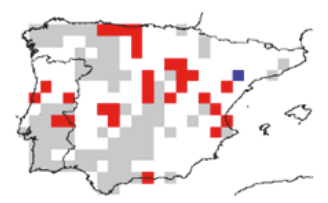

Drought magnitude
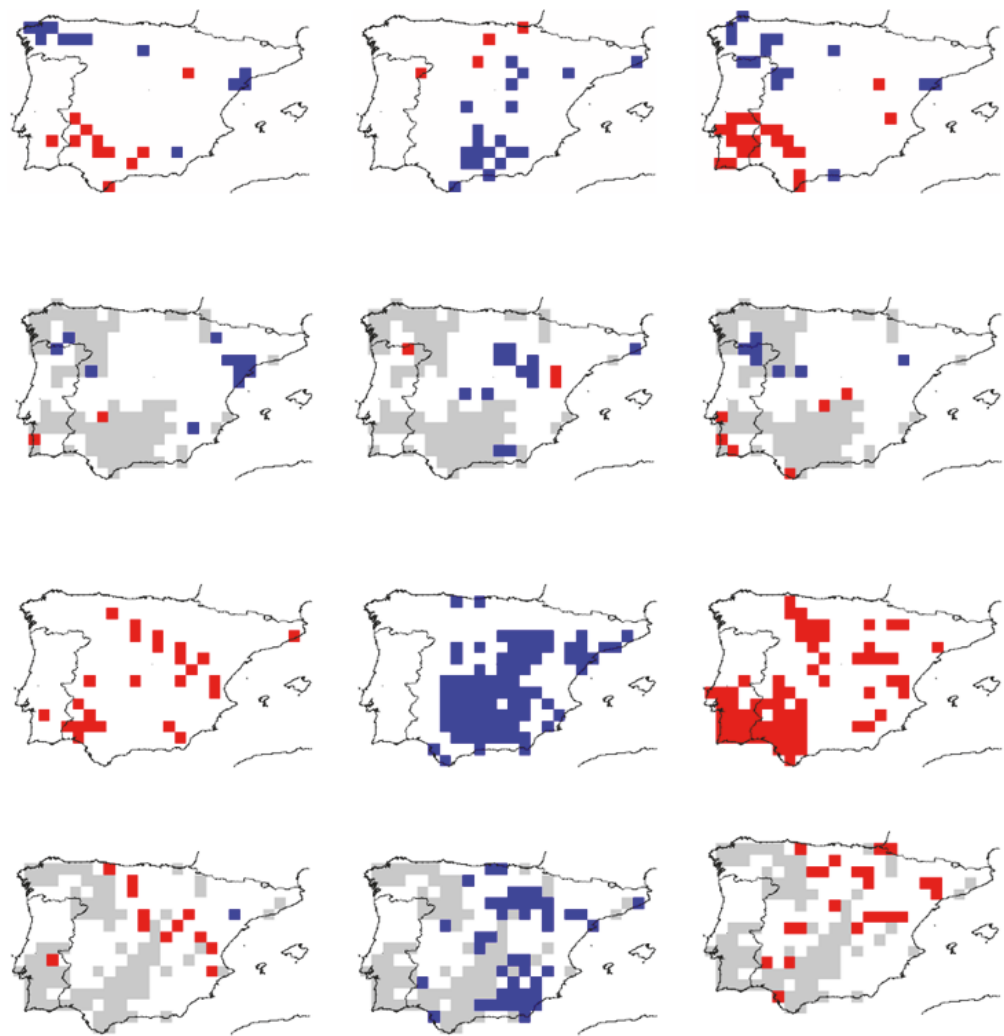

FIGURE 6: Significant trends in drought duration, drought magnitude, time between drought events, and mean intensity of droughts. Red (blue) grid points represent positive (negative) trends, and white represent no significant trend. Gray is used for the grid points where the time series of moderate/severe drought events has less than 20 points.

trends are still significant when we consider only the more severe and extreme drought events (thresholds -1.28 and -1.65 , resp.).

Table 3 presents the monthly relative frequency (\%) by which droughts are affecting more than $40 \%$ of the IP for moderate, severe, and extreme drought events. As expected, the frequency is higher for less severe droughts. In the case of moderate droughts, the frequency is lower, despite presenting higher frequencies for SPI relative to those reached by SPEI in the earlier period ( $13 \%$ and $6 \%$, resp.). However, the frequency of drought episodes increases along the century, with SPEI (34\%) and SPI (24\%) presenting the highest occurrence in the later period. The results for severe and extreme drought frequency (affecting more than $40 \%$ of the IP) depict a percentage close to zero in the first period and a significant increase of the larger and spreader drought episodes in the latest period 1975-2012.

Drought duration, magnitude, time spanned between drought events, and mean intensity were also computed considering moderate and severe droughts (i.e., using the -0.84 and -1.28 thresholds). Figure 6 presents the significant trends for the above-mentioned metrics for SPI and SPEI indices, considering only the complete period. The three subperiods were also analyzed but are not shown, since the number of grid points where the time series has at least 20 values is very small and could result in misleading interpretations. Likewise, the trend associated with extreme droughts events' characteristics (duration, drought magnitude, time between drought events, and mean drought intensity) with reduced number of points was also not considered.

In the case of the results obtained using the SPEI index for severe droughts (i.e., using the -1.28 threshold), the drought duration and magnitude trends are mostly positive. The trends in the time spanned between drought events are negative for both drought categories covering approximately $30 \%$ of the entire IP, when considering the -0.84 threshold (Figure 6, SPEI). The significant trends are located mostly over central and eastern IP. On the other hand, grid points characterized by significant trends of drought duration and drought magnitude are scattered throughout the Peninsula and do not present spatial homogeneity. However, there is an increase in both parameters over the region connecting northern and southeastern IP, for both thresholds (Figure 6, SPEI). Concerning the trends computed using SPI and the -0.84 threshold (Figure 6, SPI), the results mirrored the spatial pattern observed for SPI trends (Figure 4). Although presenting a smaller number of grid points with significant trends, the North-South difference is still visible on both duration and magnitude (Figure 6, SPI). 


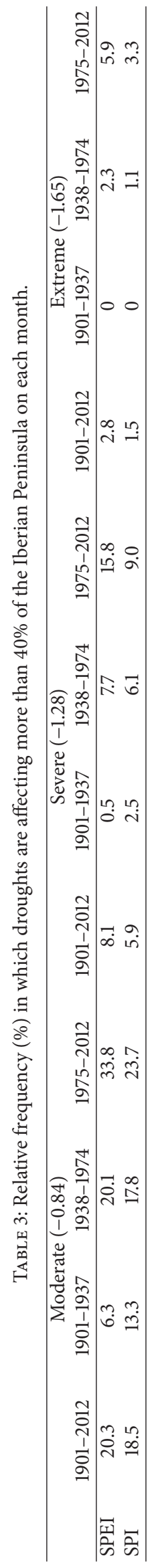




\section{Discussion and Conclusions}

Several authors have discussed the role of including $\mathrm{ET}_{0}$ in the trend analysis of droughts at global $[25,31,32,38,56]$, continental $[35,67]$, and national or regional scales $[68,69]$. Using distinct datasets and/or different drought indices for various regions of the Mediterranean basin and considering shorter periods, several authors identified colder/wetter and warmer/dryer periods over different regions [22, 25, 44, 70, 71]. A marked pattern of decreased precipitation spread over the IP, with the exception of the NW of the Peninsula, was also identified by Merino et al. [72], using the Global Precipitation Climatology Center database, and by Coll et al. [26], which used data from meteorological stations during the period 1906-2010. Other studies based on meteorological stations over Spain and the entire IP have also shown a general increase of $\mathrm{ET}_{0}$ for the last 50 years $[28,69]$. On the other hand, Coll et al. [26] showed a general increase in temperature and a clear drying trend for most of the IP when using SPEI.

The first goal of this work was to evaluate for the first time such trends for the entire IP during the long-term period of 112 years (1901-2012), using the high-resolution $(0.5 \times 0.5$ degrees) gridded database available by Climate Research Unit TS3.21 [45], and evaluate its usefulness to assess drought evolution in the entire IP by means of two drought indices, namely, SPI and SPEI. An additional motivation of this analysis was related to the low spatial representation of meteorological stations over Portugal in the majority of the works mentioned above, namely, in the case of the works by Coll et al. [26] that used only two stations in Portugal and 1 station in the northwestern region of Spain. The drought indices obtained with the averaged precipitation and $\mathrm{ET}_{0}$ are consistent with the results obtained by Coll et al. [26]. The analysis of the indices in our work revealed a nonstationarity of the trends particularly significant in the first and third periods, consistent with the nonstationarity of the $\mathrm{ET}_{0}$ trends, but virtually absent during the central period encompassing the 1940s, 1950s, and 1960s. This trend analysis ensured the second goal of this work that was to assess for the first time the drought trends for three successive subperiods within the long-term period. The third objective of this work was to assess if the observed trend of dryness severity and area affected by drought in the IP as obtained using CRU dataset is similar to the ones obtained by other authors. Finally, it was also aimed to assess for the first time the longterm trends of drought duration, drought magnitude, time between drought events, and mean drought intensity at grid point scale, allowing the identification of drought-prone areas of the IP.

The estimation of $\mathrm{ET}_{0}$ considered its influence on longterm trends of drought indices reported by Sheffield et al. [32] and so the Hargreaves method was chosen, since it avoids the overestimation of drought trends $[32,55]$. The analysis of the spatial distribution of $\mathrm{ET}_{0}$ over the IP showed a general increase in this meteorological variable during the long-term period of 1901-2012, which is consistent with the general increase in temperature observed using meteorological stations covering most of the 20th century [26, 44], as well as covering more recent years [43]. This feature highlights the need to compare the ability of SPI and SPEI indices to monitor drought trends on IP. As expected, the analysis of the averages of SPI and SPEI time series over the IP showed an increase of dryness during the last 112 years, mainly due to the increase in evapotranspiration [28].

The analysis of the spatial pattern of precipitation in the long-term period showed a decrease of precipitation on most of the territory, except for the Northwest of the Peninsula in accordance with the works mentioned before $[26,72]$. On the other hand, the spatial patterns of $\mathrm{ET}_{0}$ present a general tendency to rise despite being less significant when the analysis is performed for the individual subperiods. Consequently, the impact of both precipitation and $\mathrm{ET}_{0}$ is evident in the results obtained for SPEI, since it presents more significant trends than SPI, being moreover mostly negative. However, some positive trends are observed over the northwestern area, where the rise in precipitation seems to exceed the growth of $\mathrm{ET}_{0}$. Nevertheless, the influence of $\mathrm{ET}_{0}$ is more evident in the differences obtained between SPEI and SPI, as the spatial distribution of the trends is almost identical to the distribution of $\mathrm{ET}_{0}$ trends, although with opposite signal, as expected. Moreover, the similarity of our results for the long-term period to the ones obtained by Coll et al. [26] indicate that although the level of confidence in the earlier years of the CRU TS3.21 dataset is low, this does not appear to influence the results obtained here for the longer period. Thus, we are confident that the use of the longterm CRU TS3.21 dataset in southern Europe will contribute to enhancing the knowledge of drought events, its spatial evolution, and characteristics in the last century and at early $21 s t$ century and that the use of data prior to the year 1950 does not pose a problem to this type of analysis.

The analysis of the three subperiods pointed to different behaviors in terms of drought trends, highlighting the need to perform a separate analysis at regional scale for the IP [35] aiming to reduce the vulnerability of the different regions and minimize losses induced by drought [36]. The results for the three smaller subperiods (1901-1937, 1938-1974, and 1975-2012) point to a generalized trend towards higher evaporative demand in the first and last period and of a lower $\mathrm{ET}_{0}$ in the intermediate period. While in the case of the first period a small area with positive trends of $\mathrm{ET}_{0}$ was found in the southeastern region, in the last period a corresponding area was found in the eastern part of Portugal. The spatial patterns of precipitation trends in the first 3 decades of the 20th century are similar to the spatial patterns found for the long-term period, with negative trends in the South and Southwest and positive trends in the North and Northwest of the IP. Moreover, a clear trend for wet conditions was observed in the intermediate period. Finally, less significant trends were observed in the last period and mainly concentrated in the North, where they are mostly negative, thus showing a shift in the trend. The comparison with other results should be performed carefully, not only because most works analyze annual, seasonal, or monthly precipitation, but also because the time periods used are rarely coincident. Our results are generally in good agreement with the precipitation trends obtained by De Luis et al. [73], who reported negative trends in seasonal precipitation in Spain on all seasons except 
Autumn, on the period 1946-2005, when analyzing a gridded dataset, although a previous work using meteorological stations showed a more complex pattern on Eastern Spain, where both negative and positive significant trends were reported on the period 1951-2000 [74]. In Portugal, De Lima et al. [71] found mostly nonsignificant trends in the periods 1945-1975 and 1976-2007 and a small number of significant and negative trends in the northern region in the second of these periods, which also support our findings for the second and third subperiods.

Consequently, the impact of both precipitation and $\mathrm{ET}_{0}$ is evident in the results obtained for SPEI, namely, in the latest period that showed a widespread tendency for dryer conditions (with the exception for the western region over Portugal), a pattern that is not so clear with SPI. In the case of the two first subperiods the spatial patterns of SPI and SPEI trends are consistent, showing a clear tendency for wet conditions in the intermediate period and over the Northwest and North of the IP in the first period. A negative trend of both drought indicators was observed in the South of the IP, presenting higher number of significant trends in the case of SPEI. Therefore, the results for the three smaller subperiods (1901-1937, 1938-1974, and 1975-2012) point to a generalized trend towards wetter conditions in the intermediate period and widespread drier conditions in the two other periods. The exception is central Portugal, which shows a positive trend, caused by an increase in precipitation and a decrease in $\mathrm{ET}_{0}$. This result is also reported by Vicente-Serrano et al. [28], when analyzing SPI and SPEI calculated with data obtained from meteorological stations for the period 1961-2011. The works mentioned above failed to report this wetting trend, probably due to the shorter time period being coincident with the intermediate period considered in the present study. The tendency for dryness, as obtained by the difference between SPEI and SPI in the last period, is in agreement with the findings of VicenteSerrano et al. [28] for the IP that showed an increase of drought severity during the last 50 years, as a consequence of an increase of atmospheric evaporative demand resulting from temperature rise. However, our results highlighted that this tendency was also observed in the first three decades of the 20th century, being interrupted by a period showing a tendency to wet conditions mainly in central IP.

The different patterns of dryness obtained in the last two periods are compatible with the findings of Páscoa et al. [50] when studying the relationship between drought events in the IP and wheat yields for two different periods (1929-1985 and 1986-2012) that were identified due to the characteristic of crop yields in both Iberian countries. They also found areas in Spain presenting negative correlations in the winter months for the period between 1929 and 1985, located in the western territory and forming a homogeneous zone with areas of negative correlation in Portugal. Additionally, Páscoa et al. [50] found for the period from 1986 to 2012 a westward spread of positive correlations between SPEI and wheat yield. A marked decrease of negative correlations was observed, accompanied by the striking decrease of significant correlations in the western Iberian territory, particularly in the Portuguese territory. These results reinforce the change of the trends' signal in the spatial domain.

Even though the spatial patterns of droughts are very complex, and in some situations close areas may be experiencing different drought conditions, the evolution of the monthly percentage of area affected by drought (using SPEI) points to a significant increase for all drought categories. It should also be noted that the increase, along the long-term period from 1901 to 2012, of very spread drought episodes (more than $40 \%$ of IP affected) was better detected with SPEI than with SPI, being the increase more accentuated in the last four decades. Vicente-Serrano et al. [28] also pointed to a rise of drought severity in the last 5 decades, together with an increased tendency for dryness and stressed that this increment is independent of the evapotranspiration approach used. Similarly, the global assessment of wetting/drying trends during the period 1948-2005 performed by Greve and coauthors [38] has identified the Southwest of the IP as one hot spot of the pattern "dry gets drier."

On the other hand, Spinoni and coauthors [25] have found a significant increase in drought frequency, duration, and severity over the IP since 1951. Following Spinoni and coauthors [25], it was our goal to assess such tendencies along the long-term period, specifically the spatial patterns of trends on drought duration and magnitude, aiming to identify the more susceptible areas in the IP. Our first results pointed out the higher number of significant trends identified using SPEI than using SPI. The signal of the trends obtained is more consistent in the case of SPEI than in case of SPI, which presents trends with opposite signals spread over certain regions of the IP. The results arising from the application of SPEI also depict an increase in the duration and magnitude of drought events, although these are scattered throughout the IP and do not present spatial homogeneity. However, the number of significant trends of duration and magnitude of moderate droughts (SPEI $<-0.84$ ) is mainly located in southern and central IP.

The tendency along the long-term period (1901-2012) of the time spanned between drought events and mean intensity of drought was also computed, presenting clear and significant spatial patterns in the case of moderate drought that were identified using SPEI. A decrease in the time spanned between drought events is evident in central IP, covering approximately $30 \%$ of the IP in the case of moderate droughts. Our results revealed to be crucial for the development of mitigation strategies as the most productive regions of cereals are in central IP [50]. Moreover, over southwestern IP a clear pattern of positive trends of drought mean intensity is observed, which are coincident with the area affected in the last severe drought events of 2005 and 2012 $[9,10,18]$ that were responsible by severe losses in crop yields and energy $[8,9]$. When studying the streamflow droughts in the IP, Lorenzo-Lacruz et al. [75] also obtained an increase in drought duration and magnitude in similar areas. There are many factors that explain these results, mainly related to the high regulation of rivers in the IP, but the authors point to precipitation as an important factor.

Despite agreeing with the previous studies performed on the last 5/6 decades, our results also constitute the 
first long-term evaluation with 112 years of CRU dataset, presenting additionally a regional character over the IP, a region that presents itself as an important hot spot in the Mediterranean region [24]. Nevertheless, the IPCC report on extremes emphasizes the large uncertainties associated with observed droughts trends around the world [1]. Seneviratne et al. [34] also pointed out the need of further research about these uncertainties, including studies of paleoclimate that relate specific changes in temperature with drought. Thus, we are convinced that our study brings new insights about temperature, $\mathrm{ET}_{0}$, and drought behaviors within a long-term period of 112 years starting in the beginning of the last century. We are also confident that our results concerning the identification of regions over the IP that showed a clear pattern of increased dryness severity, drought intensity, and a decrease of time between consecutive drought events will be very useful, supplying managers with robust tools aiming for the development of mitigation plans that will be crucial in the case of the occurrence of more intense and frequent drought events over the IP within a context of climate change [39].

\section{Disclosure}

An abstract version of this manuscript was presented at the 2015 EGU General Assembly.

\section{Conflicts of Interest}

The authors declare that they have no conflicts of interest.

\section{Acknowledgments}

This work was partially supported by national funds through FCT (Fundação para a Ciência e a Tecnologia, Portugal) under Project IMDROFLOOD (WaterJPI/0004/2014) and the research grant attributed to Ana Russo (SFRH/BPD/ 99757/2014).

\section{References}

[1] C. B. Field, V. Barros, T. F. Stocker, and Q. Dahe, Managing the Risks of Extreme Events and Disasters to Advance Climate Change Adaptation: A Special Report of Working Groups I and II of the Intergovernmental Panel on Climate Change, Cambridge University Press, Cambridge, UK, 2012.

[2] E. L. Birch, "A Review of "Climate Change 2014: Impacts, Adaptation, and Vulnerability" and "Climate Change 2014: Mitigation of Climate Change", Journal of the American Planning Association, vol. 80, no. 2, pp. 184-185, 2014.

[3] S. I. Seneviratne, D. Lüthi, M. Litschi, and C. Schär, "Land-atmosphere coupling and climate change in Europe," Nature, vol. 443, no. 7108, pp. 205-209, 2006.

[4] M. G. Donat, L. V. Alexander, H. Yang et al., "Updated analyses of temperature and precipitation extreme indices since the beginning of the twentieth century: the HadEX2 dataset," Journal of Geophysical Research: Atmospheres, vol. 118, no. 5, pp. 2098-2118, 2013.

[5] J. Sillmann, V. V. Kharin, F. W. Zwiers, X. Zhang, and D. Bronaugh, "Climate extremes indices in the CMIP5 multimodel ensemble: Part 2. Future climate projections," Journal of Geophysical Research: Atmospheres, vol. 118, no. 6, pp. 2473-2493, 2013.

[6] S. I. Seneviratne, M. G. Donat, B. Mueller, and L. V. Alexander, "No pause in the increase of hot temperature extremes," Nature Climate Change, vol. 4, no. 3, pp. 161-163, 2014.

[7] C. C. Ummenhofer and G. A. Meehl, "Extreme weather and climate events with ecological relevance: a review," Philosophical Transactions of the Royal Society B: Biological Sciences, vol. 372, no. 1723, p. 20160135, 2017.

[8] R. García-Herrera, D. Paredes, R. M. Trigo et al., "The outstanding 2004/05 drought in the Iberian Peninsula: Associated atmospheric circulation," Journal of Hydrometeorology, vol. 8, no. 3, pp. 483-498, 2007.

[9] C. Gouveia, R. M. Trigo, and C. C. DaCamara, "Drought and vegetation stress monitoring in Portugal using satellite data," Natural Hazards and Earth System Sciences, vol. 9, no. 1, pp. 185195, 2009.

[10] R. M. Trigo, J. Añel, D. Barriopedro et al., "The record winter drought of 2011-12 in the Iberian Peninsula," in Explaining Extreme Events of 2012 from a Climate Perspective, T. C. Peterson, M. P. Hoerling, P. A. Stott, and S. Herring, Eds., vol. 94, pp. S41-S45, Bulletin of the American Meteorological Society, 9 edition, 2013.

[11] J. V. Vogt, P. Barbosa, B. Hofer et al., "Developing a European Drought Observatory for Monitoring, Assessing and Forecasting Droughts across the European Continent," American Geophysical Union Fall Meeting Abstracts 1, NH24A-07, 2011.

[12] B. Lloyd-Hughes, "The impracticality of a universal drought definition," Theoretical and Applied Climatology, vol. 117, no. 3-4, pp. 607-611, 2014.

[13] A. Robock, K. Y. Vinnikov, G. Srinivasan et al., "The global soil moisture data bank," Bulletin of the American Meteorological Society, vol. 81, no. 6, pp. 1281-1299, 2000.

[14] R. R. Heim Jr., "Drought indices: A review," in Drought: A Global Assessment, D. A. Wilhite, Ed., pp. 159-167, Routledge, 2000.

[15] J. Keyantash and J. Dracup, "The quantification of drought: an evaluation of drought indices," Bulletin of the American Meteorological Society, vol. 83, pp. 1167-1180, 2002.

[16] S. M. Vicente-Serrano, S. Beguería, and J. I. López-Moreno, "A multiscalar drought index sensitive to global warming: the standardized precipitation evapotranspiration index," Journal of Climate, vol. 23, no. 7, pp. 1696-1718, 2010.

[17] F. N. Kogan, "Global drought watch from space," Bulletin of the American Meteorological Society, vol. 78, no. 4, pp. 621-636, 1997.

[18] C. M. Gouveia, A. Bastos, R. M. Trigo, and C. C. Dacamara, "Drought impacts on vegetation in the pre- and post-fire events over Iberian Peninsula," Natural Hazards and Earth System Sciences, vol. 12, no. 10, pp. 3123-3137, 2012.

[19] W. C. Palmer, Meteorological Drought, Office of Climatology, US Weather Bureau Research Paper NO. 45, Washington, DC, USA, 1965.

[20] T. B. N. McKee, J. Doesken, and J. Kleist, “The relationship of drought frequency and duration to time scales," in Eight Conference on Applied Climatology, pp. 179-184, Anaheim, Calif, USA, 1993.

[21] N. Wells, S. Goddard, and M. J. Hayes, "A self-calibrating palmer drought severity index," Journal of Climate, vol. 17, pp. 23352351, 2004.

[22] P. M. Sousa, R. M. Trigo, P. Aizpurua, R. Nieto, L. Gimeno, and R. Garcia-Herrera, "Trends and extremes of drought indices 
throughout the 20th century in the Mediterranean," Natural Hazards and Earth System Sciences, vol. 11, no. 1, pp. 33-51, 2011.

[23] N. B. Guttman, "Accepting the standardized precipitation index: a calculation algorithm," JAWRA Journal of the American Water Resources Association, vol. 35, no. 2, pp. 311-322, 1999.

[24] , The Climate of the Mediterranean Region: From the Past to the Future, P. Lionello, Ed., Elsevier, 2012.

[25] J. Spinoni, G. Naumann, J. Vogt, and P. Barbosa, "European drought climatologies and trends based on a multi-indicator approach," Global and Planetary Change, vol. 127, pp. 50-57, 2015.

[26] J. Coll, E. Aguilar, and L. Ashcroft, "Drought variability and change across the Iberian Peninsula," Theoretical and Applied Climatology, vol. 130, no. 3-4, pp. 901-916, 2016.

[27] G. van der Schrier, K. R. Briffa, P. D. Jones, and T. J. Osborn, "Summer moisture variability across Europe," Journal of Climate, vol. 19, no. 12, pp. 2818-2834, 2006.

[28] S. M. Vicente-Serrano, J.-I. Lopez-Moreno, S. Beguería et al., "Evidence of increasing drought severity caused by temperature rise in southern Europe," Environmental Research Letters, vol. 9, no. 4, Article ID 044001, 2014.

[29] B. Lloyd-Hughes and M. A. Saunders, "A drought climatology for Europe," International Journal of Climatology, vol. 22, no. 13, pp. 1571-1592, 2002.

[30] I. Bordi, K. Fraedrich, and A. Sutera, "Observed drought and wetness trends in Europe: An update," Hydrology and Earth System Sciences, vol. 13, no. 8, pp. 1519-1530, 2009.

[31] A. Dai, K. E. Trenberth, and T. Qian, "A global dataset of Palmer Drought Severity Index for 1870-2002: relationship with soil moisture and effects of surface warming," Journal of Hydrometeorology, vol. 5, no. 6, pp. 1117-1130, 2004.

[32] J. Sheffield, E. F. Wood, and M. L. Roderick, "Little change in global drought over the past 60 years," Nature, vol. 491, no. 7424, pp. 435-438, 2012.

[33] B. Orlowsky and S. I. Seneviratne, "Global changes in extreme events: regional and seasonal dimension," Climatic Change, vol. 110, no. 3-4, pp. 669-696, 2012.

[34] S. I. Seneviratne, N. D. Nicholls, C. M. Easterling et al., "Changes in climate extremes and their impacts on the natural physical environment," in Managing the Risks of Extreme Events and Disasters to Advance Climate Change Adaptation, Field., C. B, V. Barros et al., Eds., pp. 109-230, A Special Report of Working Groups I and II of the Intergovernmental Panel on Climate Change (IPCC), Cambridge University Press, NY, USA, 2012.

[35] D. L. Ficklin, J. T. Maxwell, S. L. Letsinger, and H. Gholizadeh, "A climatic deconstruction of recent drought trends in the United States," Environmental Research Letters, vol. 10, no. 4, Article ID 044009, 2015.

[36] B. Bonaccorso, D. J. Peres, A. Cancelliere, and G. Rossi, "Large Scale Probabilistic Drought Characterization Over Europe," Water Resources Management, vol. 27, no. 6, pp. 1675-1692, 2013.

[37] S. M. Vicente-Serrano, S. Beguería, J. Lorenzo-Lacruz et al., "Performance of drought indices for ecological, agricultural, and hydrological applications," Earth Interactions, vol. 16, no. 10, pp. 1-27, 2012.

[38] P. Greve, B. Orlowsky, B. Mueller, J. Sheffield, M. Reichstein, and S. I. Seneviratne, "Global assessment of trends in wetting and drying over land," Nature Geoscience, vol. 7, no. 10, pp. 716-721, 2014.

[39] M. Hoerling, J. Eischeid, J. Perlwitz, X. Quan, T. Zhang, and P. Pegion, "On the increased frequency of mediterranean drought," Journal of Climate, vol. 25, no. 6, pp. 2146-2161, 2012.
[40] P. D. Jones, M. New, D. E. Parker, S. Martin, and I. G. Rigor, "Surface air temperature and its changes over the past 150 years," Reviews of Geophysics, vol. 37, no. 2, pp. 173-199, 1999.

[41] T. R. Karl, R. W. Knight, and B. Baker, “The record breaking global temperatures of 1997 and 1998: Evidence for an increase in the rate of global warming?" Geophysical Research Letters, vol. 27, no. 5, pp. 719-722, 2000.

[42] A. M. G. Klein Tank and G. P. Können, "Daily surface air temperature and precipitation dataset 1901-1999 for European Climate Assessment (ECA)," Journal of Climate, vol. 22, pp. 14411453, 2002.

[43] A. M. Ramos, R. M. Trigo, and F. E. Santo, "Evolution of extreme temperatures over Portugal: Recent changes and future scenarios," Climate Research, vol. 48, no. 2-3, pp. 177-192, 2011.

[44] M. Brunet, P. D. Jones, J. Sigró et al., "Temporal and spatial temperature variability and change over Spain during 18502005," Journal of Geophysical Research: Atmospheres, vol. 112, no. 12, Article ID D12117, 2007.

[45] I. Harris, P. D. Jones, T. J. Osborn, and D. H. Lister, "Updated high-resolution grids of monthly climatic observations-the CRU TS3.10 Dataset," International Journal of Climatology, vol. 34, no. 3, pp. 623-642, 2013.

[46] M. Macias-Fauria, A. W. R. Seddon, D. Benz, P. R. Long, and K. Willis, "Spatiotemporal patterns of warming," Nature Climate Change, vol. 4, no. 10, pp. 845-846, 2014.

[47] M. New, M. Hulme, and P. Jones, "Representing TwentiethCentury SpaceTime Climate Variability. Part II: Development of," Monthly Grids of Terrestrial Surface Climate. J. Climate, vol. 13, Article ID 190196, pp. 2217-2238, 2000.

[48] T. D. Mitchell and P. D. Jones, "An improved method of constructing a database of monthly climate observations and associated high-resolution grids," International Journal of Climatology, vol. 25, no. 6, pp. 693-712, 2005.

[49] A. C. Russo, C. M. Gouveia, R. M. Trigo, M. L. Liberato, and C. C. DaCamara, "The influence of circulation weather patterns at different spatial scales on drought variability in the Iberian Peninsula," Frontiers in Environmental Science, vol. 3, 2015.

[50] P. Páscoa, C. M. Gouveia, A. Russo, and R. M. Trigo, “The role of drought on wheat yield interannual variability in the Iberian Peninsula from 1929 to 2012," International Journal of Biometerology, vol. 61, no. 3, pp. 439-451, 2017.

[51] H. L. Penman, "Natural evaporation from open water, bare soil, and grass," in Proceedings of the. Royal Society of London A193, pp. 120-146, 1948.

[52] H. L. Penman, "Vegetation and hydrology," Technichal Communication No. 533, Commonwealth Bureau of Soils, Harpenden, England, 1963.

[53] R. G. Allen, M. Smith, A. Perrier, and L. S. Pereira, "An update for the definition of reference evapotranspiration," International Comission of Irrigation and Drainage Bulletin, vol. 43, pp. 1-34, 1994.

[54] C. W. Thornthwaite, "An approach toward a rational classification of climate," Geographical Review, vol. 38, pp. 55-94, 1948.

[55] G. H. Hargreaves and Z. A. Samani, "Reference crop evapotranspiration from temperature," Applied Engineering in Agriculture, vol. 1, no. 2, pp. 96-99, 1985.

[56] J. Spinoni, G. Naumann, and J. V. Vogt, "Pan-European seasonal trends and recent changes of drought frequency and severity," Global and Planetary Change, vol. 148, pp. 113-130, 2017.

[57] S. Beguería, S. M. Vicente-Serrano, F. Reig, and B. Latorre, "Standardized precipitation evapotranspiration index (SPEI) 
revisited: parameter fitting, evapotranspiration models, tools, datasets and drought monitoring," International Journal of Climatology, vol. 34, no. 10, pp. 3001-3023, 2014.

[58] M. J. Esteban-Parra, F. S. Rodrigo, and Y. Castro-Diez, "Spatial and temporal patterns of precipitation in Spain for the period 1880-1992," International Journal of Climatology, vol. 18, pp. 1557-1574, 1998.

[59] R. M. Trigo and C. C. DaCamara, "Circulation weather types and their influence on the precipitation regime in Portugal," International Journal of Climatology, vol. 20, no. 13, pp. 15591581, 2000.

[60] C. T. Agnew, "Using the SPI to identify drought," Drought Network News, vol. 12, no. 1, pp. 6-12, 2000.

[61] S. M. Vicente-Serrano, J. I. López-Moreno, A. Drumond et al., "Effects of warming processes on droughts and water resources in the NW Iberian Peninsula (1930-2006)," Climate Research, vol. 48, no. 2-3, pp. 203-212, 2011.

[62] K. H. Hamed and A. Ramachandra Rao, "A modified MannKendall trend test for autocorrelated data," Journal of Hydrology, vol. 204, no. 1-4, pp. 182-196, 1998.

[63] J. R. Lanzante, "Resistant, robust and non-parametric techniques for the analysis of climate data: theory and examples, including applications to historical radiosonde station data," International Journal of Climatology, vol. 16, no. 11, pp. 11971226, 1996.

[64] H. Theil, "A rank-invariant method of linear and polynomial regression analysis. I, II, III," Proceedings of the Koninklijke Nederlandse Akademie, vol. 53, pp. 386-392, 521-525, 1397-1412, 1950.

[65] P. K. Sen, "Estimates of the regression coefficient based on Kendall's tau," Journal of the American Statistical Association, vol. 63, pp. 1379-1389, 1968.

[66] S. M. Vicente-Serrano, "Spatial and temporal analysis of droughts in the Iberian Peninsula (1910-2000)," Hydrological Sciences Journal, vol. 51, no. 1, pp. 83-97, 2006.

[67] J. Stagge, L. M. Tallaksen, C.-Y. Xu, and H. Van Lanen, "Standardized precipitation-evapotranspiration index (SPEI): Sensitivity to potential evapotranspiration model and parameters. Hydrology in a Changing World: Environmental and Human Dimensions," in Proceedings of FRIEND-Water, Montpellier, France, 2014.

[68] V. Potop, C. Boroneanţ, M. Možný, P. Štěpánek, and P. Skalák, "Observed spatiotemporal characteristics of drought on various time scales over the Czech Republic," Theoretical and Applied Climatology, vol. 115, no. 3-4, pp. 563-581, 2014.

[69] S. M. Vicente-Serrano, C. Azorin-Molina, A. Sanchez-Lorenzo et al., "Reference evapotranspiration variability and trends in Spain, 1961-2011," Global and Planetary Change, vol. 121, pp. 2640, 2014.

[70] A. M. Ramos, N. Cortesi, and R. M. Trigo, "Circulation weather types and spatial variability of daily precipitation in the Iberian Peninsula," Frontiers in Earth Science, vol. 2, 2014.

[71] M. I. P. De Lima, F. E. Santo, A. M. Ramos, and R. M. Trigo, "Trends and correlations in annual extreme precipitation indices for mainland Portugal, 1941-2007," Theoretical and Applied Climatology, vol. 119, no. 1-2, pp. 55-75, 2014.

[72] A. Merino, L. López, L. Hermida et al., "Identification of drought phases in a 110-year record from Western Mediterranean basin: Trends, anomalies and periodicity analysis for Iberian Peninsula," Global and Planetary Change, vol. 133, pp. 96-108, 2015.
[73] M. De Luis, M. Brunetti, J. C. Gonzalez-Hidalgo, L. A. Longares, and J. Martin-Vide, "Changes in seasonal precipitation in the Iberian Peninsula during 1946-2005," Global and Planetary Change, vol. 74, no. 1, pp. 27-33, 2010.

[74] M. de Luis, J. C. González-Hidalgo, L. A. Longares, and P. Štepánek, "Seasonal precipitation trends in the Mediterranean Iberian Peninsula in second half of 20th century," International Journal of Climatology, vol. 29, no. 9, pp. 1312-1323, 2009.

[75] J. Lorenzo-Lacruz, E. Morán-Tejeda, S. M. Vicente-Serrano, and J. I. López-Moreno, "Streamflow droughts in the Iberian Peninsula between 1945 and 2005: spatial and temporal patterns," Hydrology and Earth System Sciences, vol. 17, no. 1, pp. 119-134, 2013. 

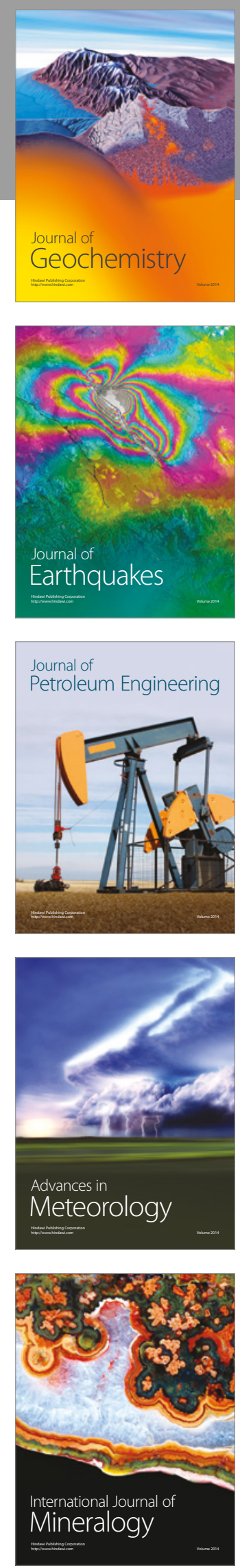
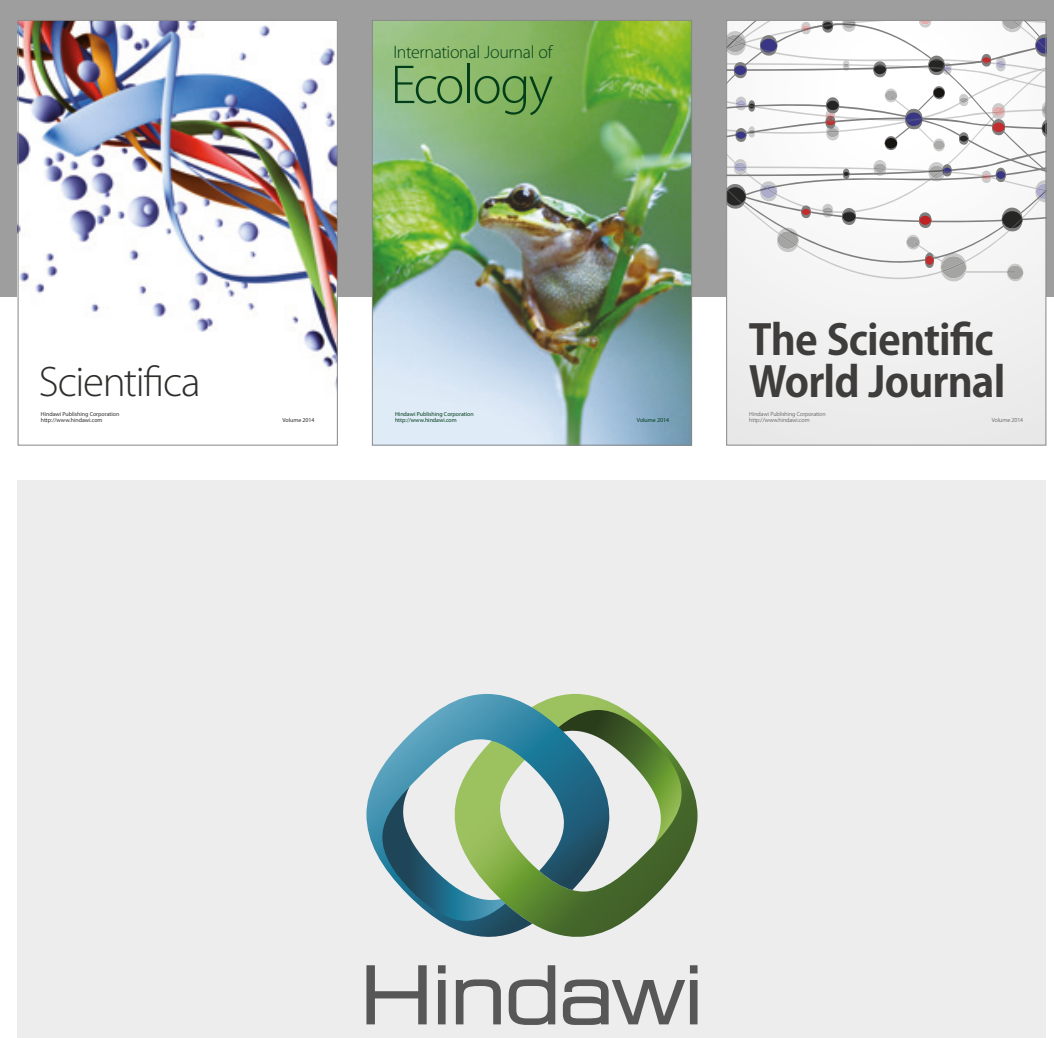

Submit your manuscripts at

https://www.hindawi.com
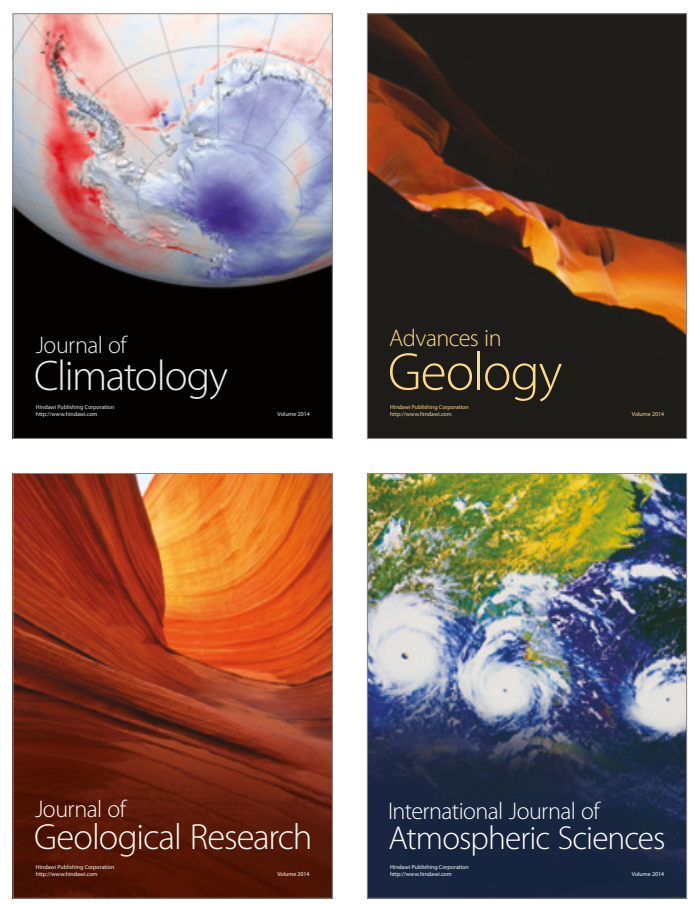

The Scientific

World Journal
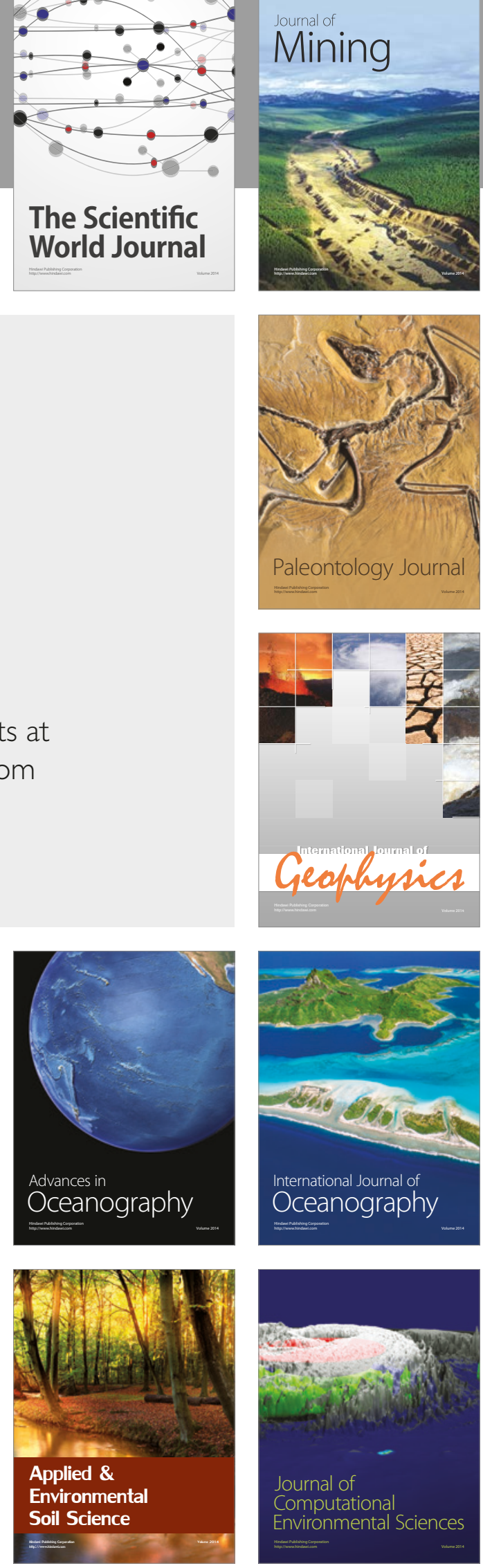